\title{
Ha-Ras stabilization mediates pro-fibrotic signals in dermal fibroblasts
}

\author{
Silvia Smaldone ${ }^{1 *}$, Jacopo Olivieri ${ }^{2}$, Gabriele Luca Gusella ${ }^{3}$, Gianluca Moroncini ${ }^{2}$, Armando Gabrielli², \\ Francesco Ramirez
}

\begin{abstract}
Background: Scleroderma (systemic sclerosis; SSc) is a clinically heterogeneous and often lethal acquired disorder of the connective tissue that is characterized by vascular, immune/inflammatory and fibrotic manifestations. Tissue fibrosis is the main cause of morbidity and mortality in SSC and an unmet medical challenge, mostly because of our limited understanding of the molecular factors and signalling events that trigger and sustain disease progression. Recent evidence has correlated skin fibrosis in SSc with stabilization of proto-oncogene Ha-Ras secondary to autoantibody stimulation of reactive oxygen species production. The goal of the present study was to explore the molecular connection between Ha-Ras stabilization and collagen I production, the main read-out of fibrogenesis, in a primary dermal fibroblast culture system that replicates the early stages of disease progression in SSc.

Results: Forced expression of proto-oncogene Ha-Ras in dermal fibroblasts demonstrated the promotion of an immediate collagen I up-regulation, as evidenced by enhanced activity of a collagen I-driven luciferase reporter plasmid and increased accumulation of endogenous collagen I proteins. Moreover, normal levels of Tgf $\beta$ transcripts and active transforming growth factor-beta (TGF $\beta$ ) implied Ha-Ras stimulation of the canonical Smad2/3 signalling pathway independently of TGF $\beta$ production or activation. Heightened Smad2/3 signalling was furthermore correlated with greater Smad3 phosphorylation and Smad3 protein accumulation, suggesting that Ha-Ras may target both Smad2/3 activation and turnover. Additional in vitro evidence excluded a contribution of ERK1/2 signalling to improper Smad3 activity and collagen I production in cells that constitutively express Ha-Ras.

Conclusions: Our study shows for the first time that constitutively elevated Ha-Ras protein levels can directly stimulate Smad2/3 signalling and collagen I accumulation independently of TGF $\beta$ neo-synthesis and activation. This finding therefore implicates the Ha-Ras pathway with the early onset of fibrosis in SSC and implicitly identifies new therapeutic targets in SSC.
\end{abstract}

\section{Background}

Wound healing is a complex and tightly regulated physiological process that involves several different cell types and a plethora of signalling molecules [1-3]. In the early phase of this process, platelets brought by the blood stream form a fibrin cloth at the site of injury that blocks bleeding (haemostasis). Increased levels of soluble signals, induced by the cell-mediated inflammatory response, subsequently promote migration and proliferation of angiogenic cells and activated fibroblasts (myofibroblasts) that synthesize extracellular matrix

\footnotetext{
* Correspondence: silvia.smaldone@mssm.edu

'Mount Sinai School of Medicine, Department of Pharmacology and Systems Therapeutics, One Gustave L Levy Place, Box 1603, New York, NY 10029, USA Full list of author information is available at the end of the article
}

(ECM) proteins, chiefly collagen I [1]. By contracting the newly synthesized ECM, myofibroblasts allow the closure of the wound where the provisional matrix is ultimately remodelled to form a scar [1]. Failure of myofibroblasts to terminate the wound healing process results in excessive accumulation and contraction of a poorly organized ECM. Unopposed myofibroblasts activation in fibrotic conditions, such as scleroderma (SSc), causes gradual and irreversible alteration of connective tissue architecture with deleterious consequences for organ function. In spite of significant investigative effort, our current knowledge of the molecular and cellular events that promote and sustain myofibroblasts activation is limited and consequently, the clinical management of affected patients remains confined to therapies

\section{Biomed Central}


that alleviate secondary symptoms rather than arresting the often fatal consequences of the fibrotic response.

Clinical findings, cell culture experiments and animal models have firmly established the prominent role that transforming growth factor- $\beta$ (TGF $\beta$ ) plays in modulating the physiological process of wound healing and in driving the pathological sequence of fibrotic responses $[2,3]$. Even though genetic or pharmacological interference of TGF $\beta$ signalling in rodents can mitigate fibrotic disease, they can also result in severe side effects due to the wide range of biological processes that involve this multifunctional cytokine [2]. It follows that a better understanding of molecular events upstream, downstream or parallel to improper TGF $\beta$ signalling represents a pre-requisite to the development of more effective and safer therapies for fibrotic conditions.

TGF $\beta$ signals through the activation of a membranereceptor serine/threonine kinase complex that phosphorylates the Smad2 and Smad3 proteins [receptoractivated Smads (R-Smad); canonical TGF $\beta$ signalling pathway] [4]. Activated R-Smad proteins associate with Smad4 to migrate into the nucleus and modulate the expression of several different genes together with transcriptional co-activators and co-repressors [4]. In addition to the canonical R-Smad pathway, TGF $\beta$ can also stimulate the activity of mitogen-activated protein kinases (MAPKs; non-canonical TGF $\beta$ signalling pathway) and MAPKs and other stress response pathways can, in turn, modulate R-Smad signalling with discrete intracellular outcomes [5]. For example, the protooncogene Ha-Ras can stimulate or inhibit R-Smad signalling, operate upstream of TGF $\beta$ by promoting its auto-induction or act independently of the canonical TGF $\beta$ signalling pathway [6-10]. Hence, complex interactions amongst different signalling pathways are believed to specify contextual responses of the cells to diverse environmental stimuli.

The Ras gene family comprises three genetically distinct but structurally related proteins (Ha-Ras, Ki-Ras and N-Ras), which operate as molecular switches that cycle between an inactive GDP (guanosine diphosphate)-bound to an active GTP (guanosine triphosphate)-bound form [11]. Ras family members have functionally distinct roles that are dictated by their intracellular localization and the cellular context [11]. Ras signalling is the nodal point of multiple extracellular cues, including the profibrotic signals of TGF $\beta$, angiotensin II, platelet-derived growth factor (PDGF) and reactive oxygen species (ROS) [7,12-14]. Recent studies of SSc cells have causally connected circulating autoantibodies against PDGF receptors (PDGFR) with the stimulation of ROS production, Ha-Ras stabilization and collagen I overproduction $[15,16]$. However, the contribution of Ha-Ras activity to SSc fibrogenesis, as well as the cross-talk between Ha-Ras and TGF $\beta$ signalling in this disease process remains to be fully explored.

It was the scope of the present study to investigate the pro-fibrotic potential of Ha-Ras signalling by using a cell culture system that replicates the downstream events previously described in SSc myofibroblasts. Our results show for the first time that constitutively elevated $\mathrm{Ha}$ Ras protein levels promote R-Smad signalling and collagen I accumulation independently of TGF $\beta$ synthesis and activation. These findings implicitly connect the Ha-Ras pathway with the onset of fibrosis through the stimulation of canonical TGF $\beta$ pathway, even though the biochemical identity of the connection was not investigated here. More generally, our work provides new insight into early disease-causing events that could in principle represent new therapeutic targets in fibrotic conditions like scleroderma.

\section{Materials and methods \\ Cell cultures}

Human fetal dermal fibroblasts (hDF; GM06111) were purchased from the Human Genetic Mutant Cell Repository (NJ, USA). Cells were maintained at $37^{\circ} \mathrm{C}$ in a sterile and humidified atmosphere of $5 \% \mathrm{CO}_{2}$. Cells were grown in Dulbecco's modified Eagle's medium (DMEM) containing 10\% fetal bovine serum (FBS; Atlanta Biologicals, GA, USA) and supplemented with streptomycin, penicillin and fungizone. Primary mouse dermal fibroblast $(\mathrm{mDF}$ ) cultures were established from the dorsal skin of 4-day-old wild-type mice and grown as described above. Several $8 \mathrm{~mm}$ sterile skin punches were made from each newborn mice, freed of the subcutaneous tissue by scraping, and laid flat individually into a $10-\mathrm{cm}^{2}$ tissue culture plate with the dermal side down. Explants were incubated at $37^{\circ} \mathrm{C}$ for 5 min to let skin adhere. Ten millilitres of medium was added into each plate and cells were allowed to migrate out of the explants for 10 days. Once confluent, cells were trypsinized and either stored in liquid nitrogen or employed immediately: in both cases, cells between passages 1 and 3 were used.

\section{Cell transfections}

Primary mDF and hDF were seeded the day before transfection at a density of $10,000 \mathrm{cells} / \mathrm{cm}^{2}$ and cultured in $0.2 \%$ FBS. Cells were transiently co-transfected using Lipofectamine 2000 (Invitrogen, CA, USA) with $0.5 \mathrm{ng}$ of the control plasmid SV40:Renilla-Luc (Promega, WI, USA) and $200 \mathrm{ng}$ of the COL1A2 (human pro- $\alpha 2$ (I) collagen gene) reporter plasmid containing wild-type or mutant TbRE (TGF $\beta$-responsive element) sites [17] or the Smad3 responsive plasmid (CAGA) ${ }_{12}$ MLP-Luc (a kind gift of Dr Joan Massagué). In some experiments, the COL1A2 reporter was transiently co- 
transfected with plasmids expressing wild-type or constitutively active (V12 variant) proto-oncogene Ha-Ras (Ha-Ras/pSG5 and ca-Ras/pSG5, respectively) or dominant-negative (N17 variant) Ha-ras (DN-Ras/pSG5; kindly provided by Dr Enrico Avvedimento), or with a plasmid expressing dominant-negative ( $\mathrm{MH} 2$ deletion) Smad3 (DN-Smad3) [17]. In other transfection experiments, hDF cultures were treated with $20 \mu \mathrm{g} / \mathrm{mL}$ neutralizing pan-TGF $\beta$ antibody (MAB1835, R\&D System, MN, USA). Luciferase assays were performed $16 \mathrm{~h}$ and $24 \mathrm{~h}$ after cell transfection and the results were evaluated as previously described [17]. Statistical analyses were performed for all of the experiments using Student's $t$ test, assuming a $P$ value of $\leq 0.05$ as significant.

\section{Lentiviral infections}

A lentivirus expressing the wild-type proto-oncogene Ha-Ras was generated by mutating Ha-Ras V12 coding sequence using the quick change II site direct mutagenesis kit (Stratagene, CA, USA) following the manufacturer's instructions. Ha-Ras coding sequence was subcloned into the VVCW/BE lentiviral expression plasmid after EcoR1/EcoRV double digestion. Ha-Ras/ $\mathrm{VVCW} / \mathrm{BE}$ or VVCW/BE empty vector were cotransfected with CMV8R8.2 and pMD.G vectors into 293T packaging cell line as described previously [18]. Viral supernatants were collected $48 \mathrm{~h}$ and $72 \mathrm{~h}$ after transfection and used to infect $\mathrm{mDF}$ cells in the presence of $10 \mu \mathrm{g} / \mathrm{mL}$ of polybrene.

\section{Immunoblots and immunocyotochemistry}

$\mathrm{mDF}$ cultured for 2 days in $0.2 \%$ FBS were infected with Ha-Ras expressing and control lenti-particles for the indicated length of time. In some experiments, the culture medium included neutralizing pan-TGF $\beta$ antibody or MEK inhibitor (PD98059) at concentrations of $10 \mu \mathrm{M}$ (Calbiochem-EMD Biosciences, NJ, USA). Cell layers were scraped into ice-cold Tris-buffered saline solution ( $\mathrm{pH} 7.4$ ) and flash frozen in liquid nitrogen. Cell extracts were prepared and assayed for total protein content using the BCA kit (Pierce, IL, USA). Protein extracts $(10-25 \mu \mathrm{g} /$ lane) were fractioned by $10 \%$ or $6 \%$ (w/v) SDS-PAGE and electroblotted onto an Immobilon-P membrane (Millipore, MA, USA). Membranes were incubated first with antibodies against $p$-Smad3 (Invitrogen) or Smad3 (Zymed; 1:1000 dilution) and subsequently with HRP-conjugated anti-rabbit IgG antibody (1:25,000 dilution; Jackson ImmunoResearch Laboratories, PA, USA). Immunoreactive products were visualized by chemiluminescence using the ECL Plus kit (Amersham Biosciences, Amersham, UK) and their relative intensity was evaluated with the aid of Adobe Photoshop software (Adobe Systems Inc, CA, USA). Actin myofibres were visualized in cells infected with
Ha-Ras and control lentivirus using antibodies against $\alpha$-smooth muscle actin ( $\alpha$ SMA; Chemicon, CA, USA).

\section{RNA analyses}

For real-time quantitative PCR (qPCR), total RNA was isolated by RNeasy Mini kit (Qiagen, Hilden, Germany) from $\mathrm{mDF}$ and used as template for complimentary DNA (cDNA) synthesis (AffinityScript multiple temperature reverse transcriptase, Stratagene). Target complimentary DNAs were amplified using SYBR Green Supermix with ROX (6-carboxy-X-rhodamine; Fermentas) on a Mastercycler ep Realplex instrument (Eppendorf, Hamburg, Germany) at the following thermal cycling conditions: $95^{\circ} \mathrm{C}$ for $10 \mathrm{~min}$ followed by 40 cycles consisting of $95^{\circ} \mathrm{C}$ for $15 \mathrm{~s}$ denaturation, $60^{\circ} \mathrm{C}$ for $30 \mathrm{~s}$ annealing and $72^{\circ} \mathrm{C}$ for $30 \mathrm{~s}$ extension. Amplification primer sets were purchased from SuperArray Bioscience Corporation (Maryland, USA. Comparative quantification was carried out using multiple replicates that were analysed in triplicate. Statistical significance was evaluated by an unpaired $t$ test assuming significant association at $P<0.05$ compared with control samples.

\section{TGF $\beta$ bioassays}

Cells for TGF $\beta$ bioassays (a kind gift of Dr Daniel Rifkin [19]) were seeded at 60,000 cells $/ \mathrm{cm}^{2}$ and then incubated with conditioned media collected from mDF, $6 \mathrm{~h}$ and $24 \mathrm{~h}$ after lentiviral infection. TGF $\beta$ activity was assessed $16 \mathrm{~h}$ later in cell lysates by measuring luciferase activity with a TD-20 luminometer (Turner Designs, CA, USA) as described previously [19]. Bioassays were performed in triplicate with multiple samples and evaluated using an unpaired $t$ test (MS Excel); significant association was defined when $P<0.05$ compared with control.

\section{Results}

\section{Proto-oncogene Ha-Ras increases COL1A2 expression} through R-Smad activation

The first set of experiments was designed to test the hypothesis that wild-type proto-oncogene Ha-Ras (hereafter referred solely as Ha-Ras) is directly involved in collagen I stimulation and to investigate the underlying mechanism. To this end, primary fetal hDFs were transiently co-transfected with a vector expressing constitutively active Ha-Ras (ca-Ras) and a luciferase reporter plasmid driven by the COL1A2 proximal promoter. The results demonstrated that ca-Ras over-expression results in a sixfold increase of COL1A2 promoter activity (Figure 1A). Ha-Ras over-expression similarly resulted in increased COL1A2 promoter activity but to a lesser extent than caRas, perhaps reflecting the inherent activation of the latter compared to the former protein (Figure 1A). Reduced COL1A2 up-regulation in hDF co-expressing $\mathrm{Ha}$-Ras and 


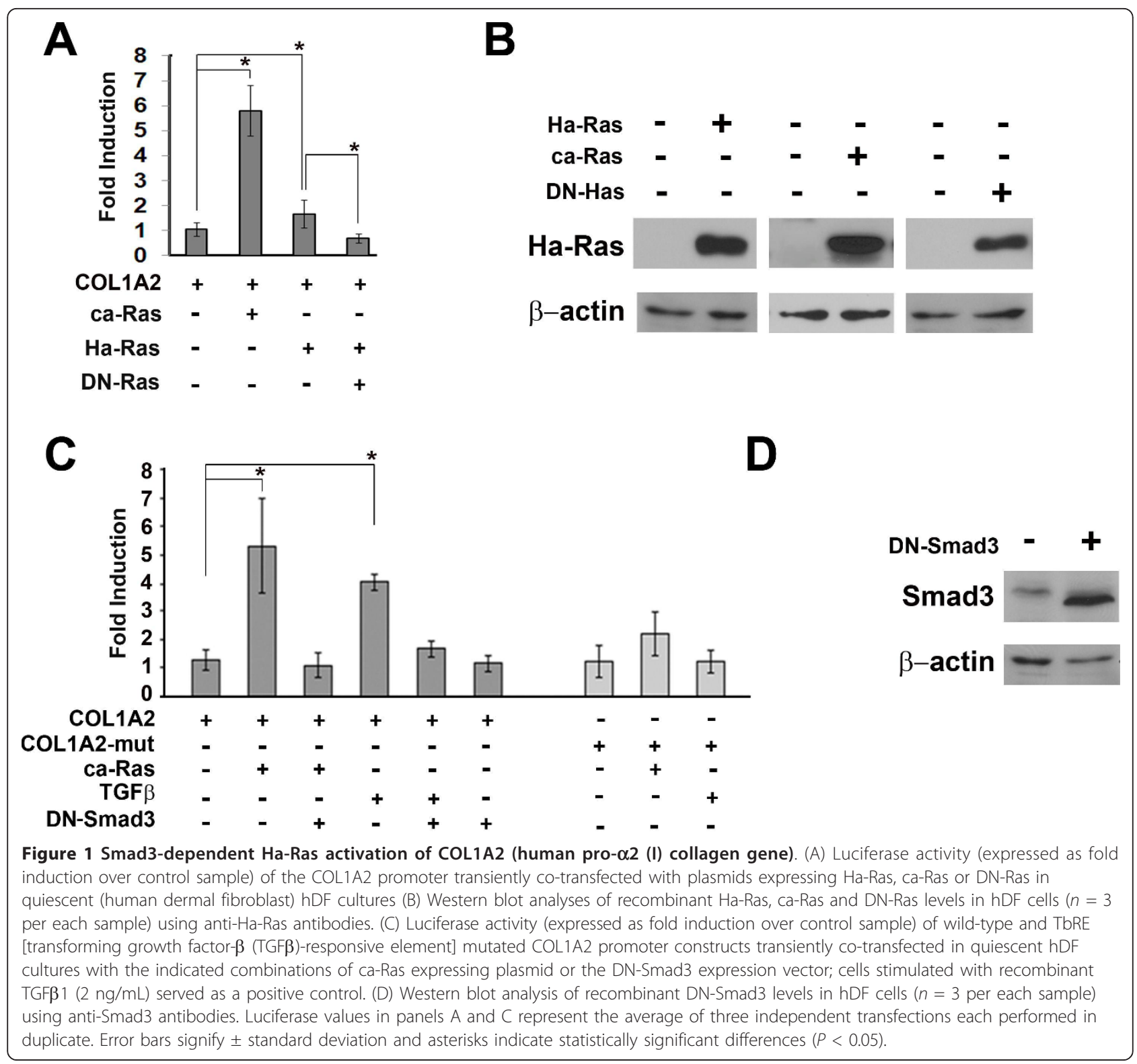

dominant-negative Ha-Ras (DN-Ras) demonstrated the specificity of the former protein action (Figure 1A). Moreover, comparable amounts of the various Ha-Ras versions excluded the formal possibility that the activity of individual expression constructs might account for the observed changes in the transcription from the COL1A2 promoter (Figure 1B).

The COL1A2 proximal promoter contains a TGF $\beta$ responsive element (TbRE) that mediates transcriptional up-regulation through the binding of a multiprotein complex that includes R-Smads, Sp1 and p300/CBP and that is also targeted by other pro-fibrotic stimuli, such as those trigged by acetaldehyde, sphingolipids and oncostatin M. [3]. Accordingly, we assessed the potential involvement of R-Smad pathway and the TbRE in HaRas-mediated collagen up-regulation. Two lines of evidence strongly suggested that Ha-Ras stimulates COL1A2 expression, in part, through the binding of activated R-Smad complexes to the TbRE. First, mutations in the Smad3-binding site of the TbRE significantly reduced ca-Ras up-regulation of the COL1A2 promoter (Figure 1C); second, co-transfection of a DNSmad3 expression plasmid abrogated ca-Ras ability to increase COL1A2 promoter activity (Figure 1C). Once again, immunoblots documented appreciable levels of recombinant DN-Smad3 (Figure 1D).

The findings of the transient cell transfection experiments were confirmed in quiescent mDFs that were 
stably infected with a lentivirus construct expressing Ha-Ras. Specifically, these analyses showed that $\mathrm{Ha}-$ Ras expressing mDF display augmented Smad3 phosphorylation and Smad3-reporter plasmid activity (Figure 2A) and collagen I production and COL1A2 promoter transcription (Figure $2 \mathrm{~B}$ and $2 \mathrm{~F}$ ), as well as more cells expressing contraction-competent actin myofibres compared to mDF infected with control lentivirus (Figure 2C). An additional outcome of HaRas overexpression in $\mathrm{mDF}$ cells included the rapid activation of ERK1/2 signalling (Figure 2A), which is part of the self-propagating loop of ROS production, Ha-Ras stabilization and collagen I accumulation in SSc $[15,16]$ and also of JNK and p38 MAPK (data not shown). As a result of its participation in SSc pathogenesis $[15,16]$, ERK1/2 signalling in Ha-Ras

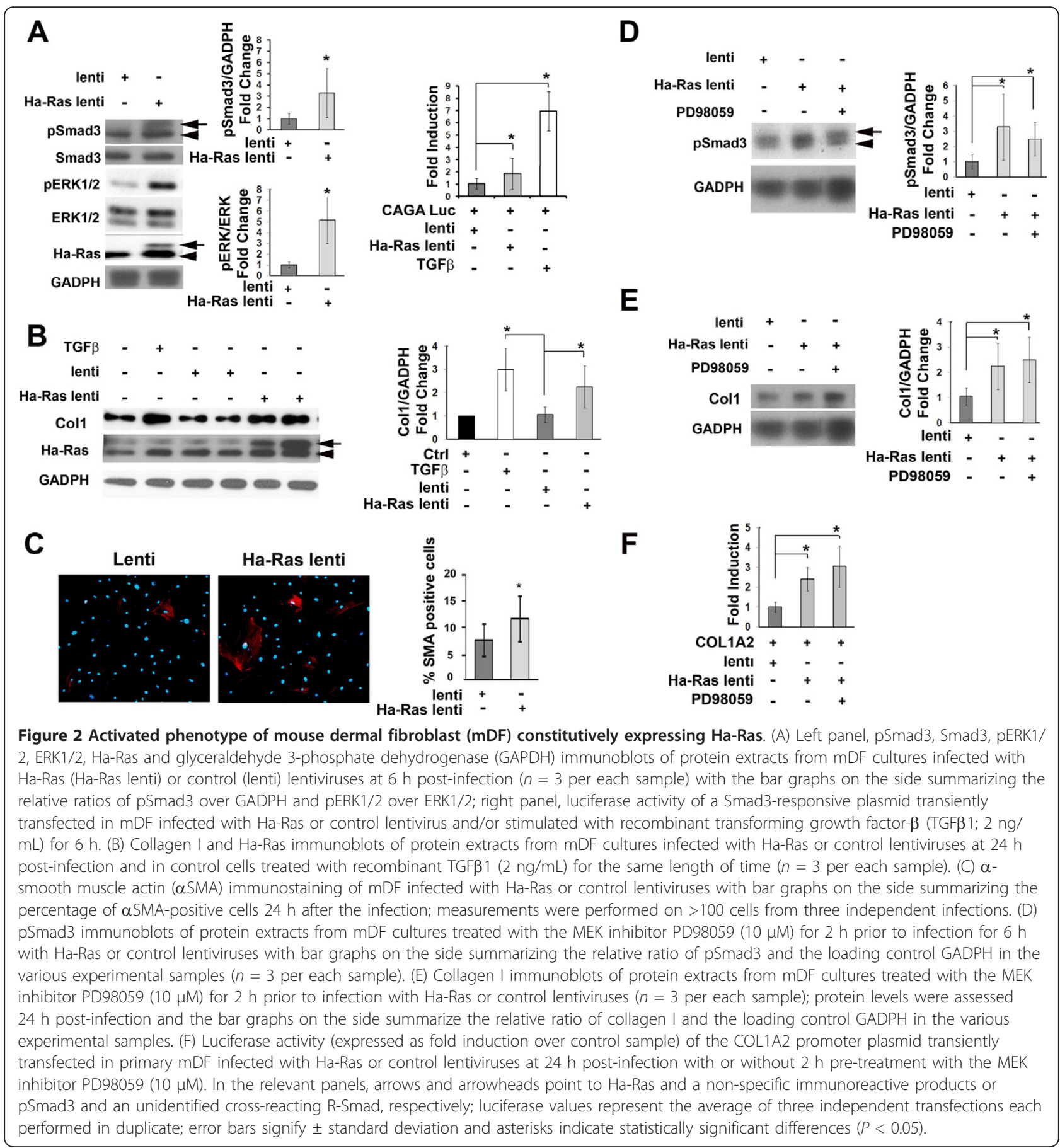


over-expressing mDF cells was blunted with the MEK inhibitor PD98059. However, ERK1/2 inhibition had no effect on Ha-Ras-induced stimulation of R-Smad signalling, COL1A2 promoter transcription or collagen I accumulation (Figure 2D-F). Time-point analyses further revealed that R-Smad stimulation is transient and peaks $6 \mathrm{~h}$ after $\mathrm{mDF}$ infection, whereas collagen I protein levels remain elevated up to $24 \mathrm{~h}$ (Figure $3 \mathrm{~A}$ and $3 \mathrm{~B}$ ). Interestingly, Ha-Ras-expressing cells also exhibited high protein levels of non-phosphorylated Smad3 at $6 \mathrm{~h}$ and $24 \mathrm{~h}$ postinfection, which were not, however, associated with increased levels of transcripts coding for Smad3 (Figure $3 C)$. We interpreted these last results to suggest that greater amounts of available Smad3 protein may also contribute to heightened pSmad3.

\section{Proto-oncogene Ha-Ras induces collagen up-regulation independently of TGF $\beta$}

Several reports have shown that Ha-Ras promotes autocrine TGF $\beta$ signalling $[6,7,20]$. The possible contribution of Ha-Ras to TGF $\beta$ production and, in turn, collagen I synthesis was therefore investigated in our cell culture systems. To this end, a pan-TGF $\beta$ antibody was employed in two complementary experiments which documented the inability of TGF $\beta$ antagonism to normalize COL1A2 promoter activity in quiescent hDF cultures transiently co-transfected with the ca-Ras expressing plasmid and in mDF cells stably infected with the Ha-Ras lentivirus (Figure 4A and 4B). These findings excluded the potential involvement of TGF $\beta$ neo-synthesis in Ha-Ras up-regulation of collagen I expression. Next, we evaluated whether Ha-Ras overexpression may promote improper activation of latent TGF $\beta$ complexes as opposed to TGF $\beta$ neo-synthesis. A bioassay, however, revealed comparable levels of active TGF $\beta$ in control and Ha-Ras over-expressing mDF cells (Figure 5A). Consistent with this and the above findings, qPCR analyses showed similar levels of TGF $\beta$ transcripts in control and Ha-Ras over-expressing $\mathrm{mDF}$ cells (Figure 5B). Collectively, the data suggested that increase of Ha-Ras protein levels in dermal fibroblasts promotes an immediate fibrotic response through the canonical R-Smad pathway without establishing an autocrine TGF $\beta$ loop.

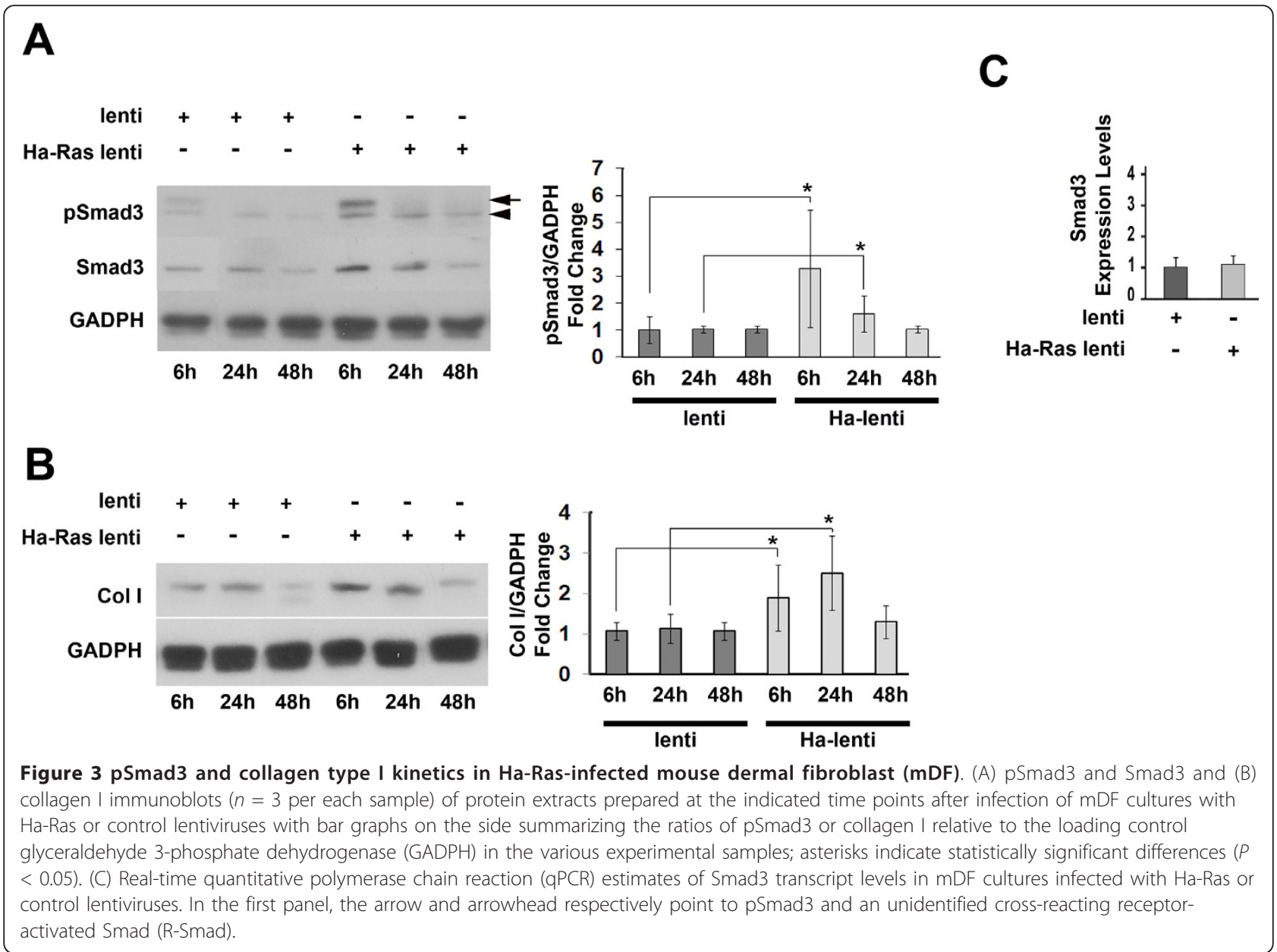




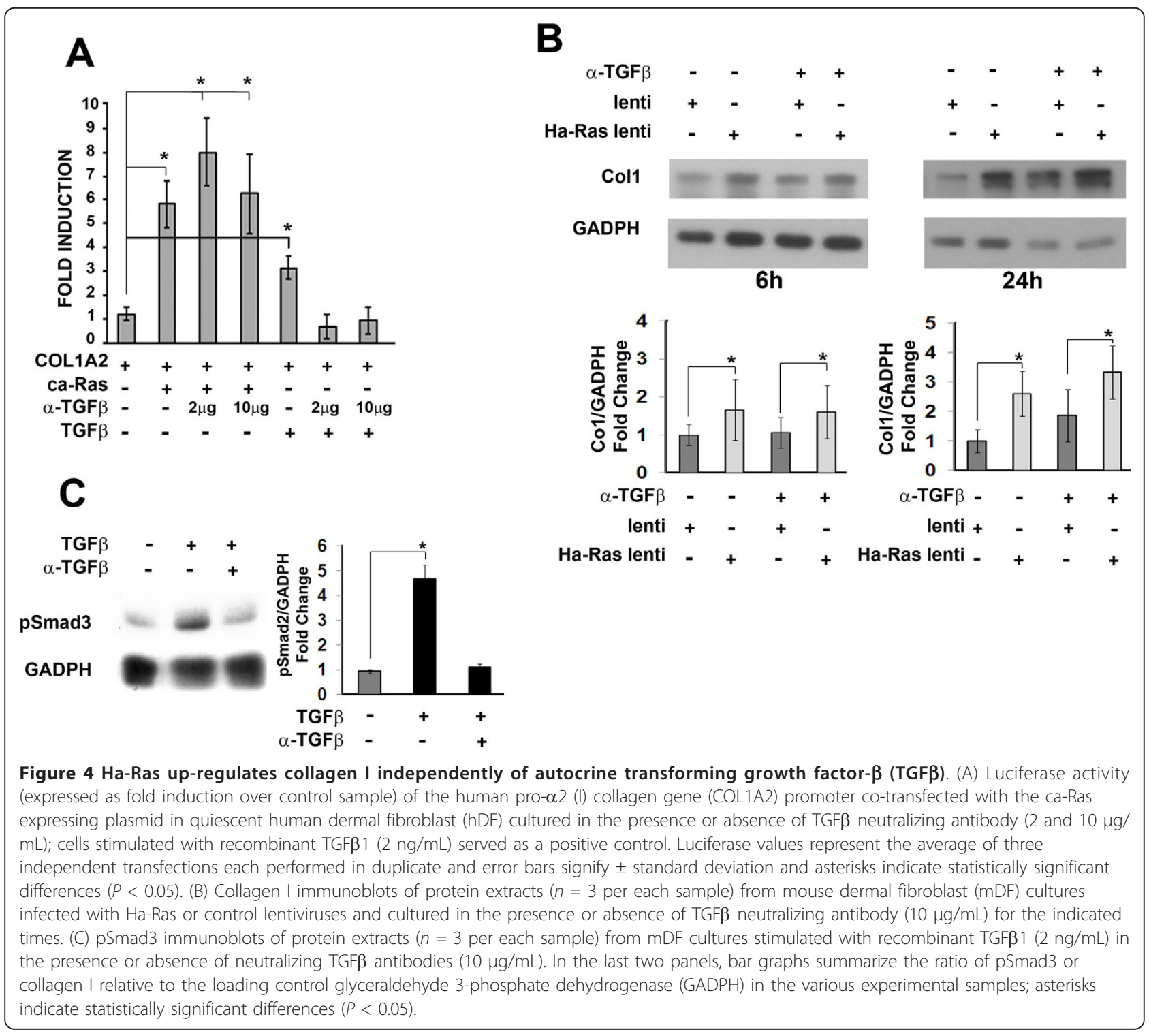

\section{Discussion}

Accumulation of myofibroblasts and disorganized ECM are the hallmarks of tissue fibrosis. TGF $\beta$ is a potent inducer of ECM synthesis and myofibroblasts contraction and a key mediator of wound healing and fibrotic responses [2]. However, TGF $\beta$ pleiotropy has largely limited therapeutical intervention in fibrotic diseases, thus stimulating an increased interest in the identification of pro-fibrotic pathways that operate downstream, upstream or in parallel with TGF $\beta$ signalling [2]. Data presented here implicate Ha-Ras stabilization in the early onset of fibrosis through TGF $\beta$-independent stimulation of R-Smad signalling.

Previous reports that Ha-Ras proto-oncogene intersects with TGF $\beta$ signalling events in several fibrotic conditions $[8,9]$, together with recent evidence that scleroderma auto-antibodies stabilize Ha-Ras levels through ROS action $[15,16]$, led us to hypothesize that increased Ha-Ras activity may influence TGF $\beta$ signalling during the early phase of the pro-fibrotic response. Through Ha-Ras overexpression in quiescent mDF, we have demonstrated that the proto-oncogene directly upregulates collagen production through TGF $\beta$-independent activation of the canonical R-Smad pathway.

Three independent lines of evidence support our conclusion. First, forced expression of DN-Smad3 and mutations in the TbRE of the COL1A2 promoter significantly reduced Ha-Ras-dependent up-regulation of the reporter plasmid. Second, lentiviral overexpression of Ha-Ras rapidly increased Smad3 signalling and R-Smaddependent reporter activity. Third, mDF pre-treatment with neutralizing pan-TGF $\beta$ antibody, or with a MEK 


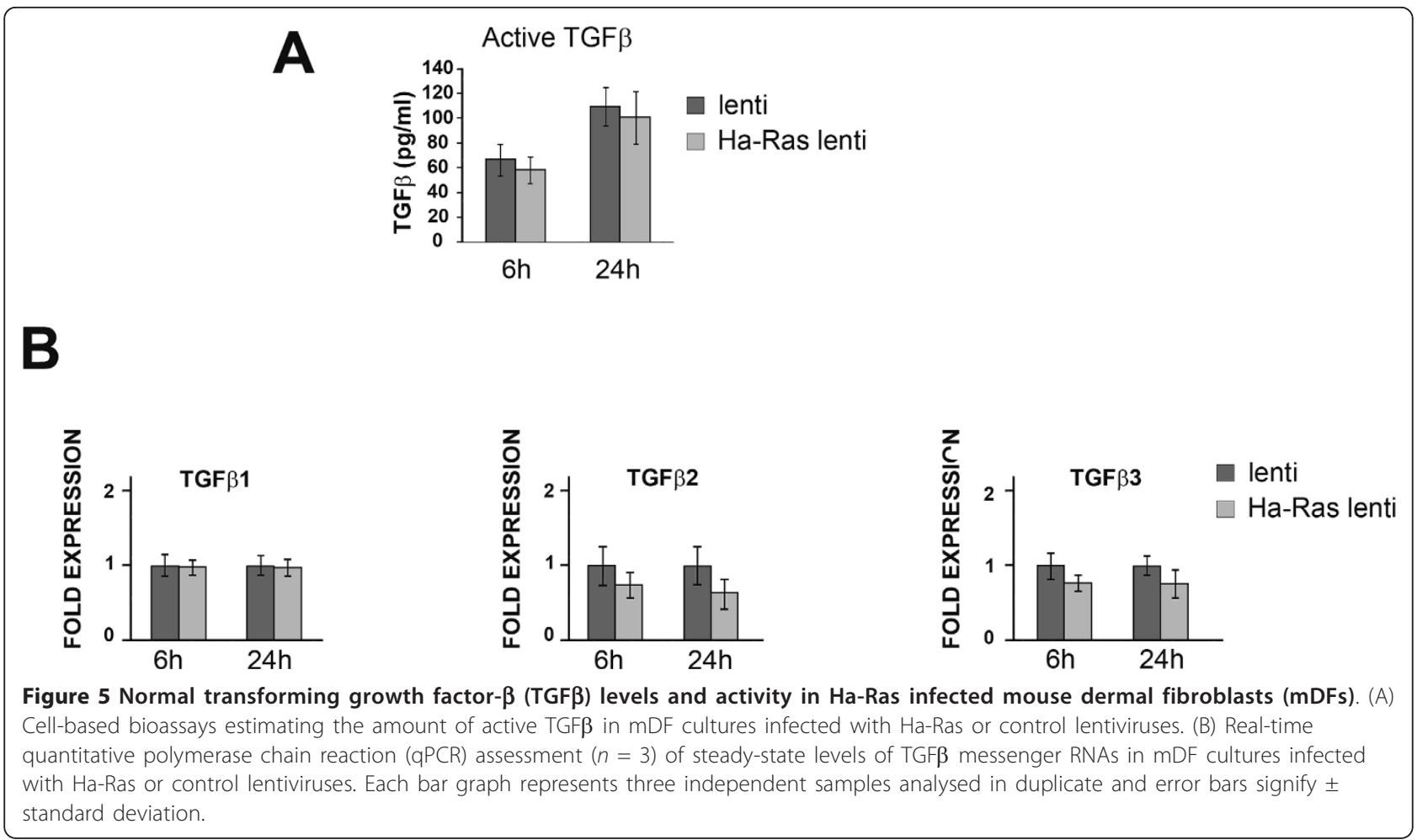

inhibitor, showed no appreciable effects on collagen accumulation and Ha-Ras-induced R-Smad activation. These results are in agreement with previous reports indicating that ligand-independent R-Smad signalling is increased in scleroderma cells and that Ha-Ras-dependent MAPK stimulation is not required for R-Smad activation $[10,21]$. In contrast to the reported participation of ERK1/2 signalling in perpetuating ROS and Ha-Ras stimulation of collagen I production in SSc fibroblasts $[15,16]$, ERK1/2 signalling is not required for collagen I up-regulation in Ha-Ras over-expressing cells. This apparent discrepancy suggests that constitutively high levels of Ha-Ras in our cell culture system do not require the postulated feed-forward loop of ERK1/2 signalling [15,16]; implicitly, our conclusion suggests that the amount of Ha-Ras is a limiting factor during the early phase of SSc fibrosis.

Protein turnover is another modulator of R-Smad3 activity in addition to protein phosphorylation [4]. The finding that $\mathrm{Ha}$-Ras overexpression in $\mathrm{mDF}$ is associated with increased Smad3 protein levels and normal amounts of Smad3 transcripts strongly suggests decreased protein degradation. Recently, the protein kinase GSK3 $\beta$ has been shown to control Smad3 ubiquitination and degradation [22]. GSK3 $\beta$ activity is negatively regulated by Ras family members and fibroblastspecific deletion of GSK3 $\beta$ in mice results in accelerated wound closure, increased fibrogenesis and excessive scarring $[23,24]$. Altogether, these reports and our results are at least consistent with the notion that augmented Smad stability in mDF overexpressing Ha-Ras accounts in part for the ligand-independent increase of canonical TGF $\beta$ signalling and collagen production. A similar situation has been described for SSc fibroblasts in which higher than normal levels of Smad3 and HaRas proteins are both associated with increased collagen accumulation [16,21].

In contrast with our observations, others have reported that oncogenic Ha-Ras (V12-Ha-Ras) dictates the response of cancer cells to TGF $\beta$ by decreasing Smad3 stability, thus suggesting a negative role of HaRas in modulating R-Smad signalling [25]. Moreover, Ha-Ras has been shown to inhibit R-Smad activity in epithelial cells and to down-regulate collagen expression in proliferating fibroblasts [26,27]. We believe that these apparent discrepancies probably reflect the multiple roles that $\mathrm{Ha}$-Ras plays in integrating the contextual responses of cells to TGF $\beta$ signalling. Our results contribute to the ongoing efforts to dissect the complex network of signalling events that drive the onset and progression of tissue fibrosis.

\section{Conclusions}

Our results provide a mechanistic insight into the role of Ha-Ras stabilization in driving collagen I overproduction during the early phase of dermal fibrosis in 
SSc by showing a direct involvement of the protooncogene in stimulating R-Smad signalling independently of TGF $\beta$ neo-synthesis or activation and of ERK1/2 signalling. This conclusion is based on in vitro evidence that correlated Ha-Ras-induced activation of $\mathrm{R}$-Smad directly to the stimulation of COL1A2 promoter reporter plasmid and with the elevation of endogenous collagen I protein. Together, our findings extend and refine recent reports that implicated circulating PDFR auto-antibody in the triggering of the ROS-mediated stabilization of Ha-Ras activity in SSc $[15,16]$. As such, they contribute to a better understanding of the early signalling events and potential therapeutic opportunities in this acquired disabling disorder of the connective tissue.

\section{Abbreviations}

aSMA: a-smooth muscle actin; ca-Ras and DN-Ras: constitutively active and dominant-negative Ha-Ras, respectively; COL1A2: human pro-a2 (I) collagen gene; DMEM: Dulbecco's modified Eagle medium; DN-Smad3: dominantnegative Smad3; ECM: extracellular matrix; hDF and mDF: human and mouse dermal fibroblasts, respectively; FBS: fetal bovine serum; MAPK: mitogenactivated protein kinase; PDGFR: platelet-derived growth factor receptor; $\mathrm{p}$ Smad, R-Smad: phosphorylated and receptor-activated Smad, respectively; QPCR: real-time quantitative polymerase chain reaction; ROS: reactive oxygen species; SSc: scleroderma; TbRE: TGF $\beta$-responsive element; TGF $\beta$ : transforming growth factor- $\beta$.

\section{Acknowledgements}

We are grateful to Dr M Kypriotou for helping with some early experiments and to Ms K Johnson for organizing the manuscript. The work was supported from grants of the National Institutes of help (AR055806) and the Scleroderma Foundation

\section{Author details}

'Mount Sinai School of Medicine, Department of Pharmacology and Systems Therapeutics, One Gustave L Levy Place, Box 1603, New York, NY 10029, USA. ${ }^{2}$ University of Ancona, Istituto di Patologia Medica e Metodolgia Clinica, Piazza Roma 22, 60121 Ancona, Italy. ${ }^{3}$ Mount Sinai School of Medicine, Department of Medicine and Nephrology, One Gustave L Levy Place, New York, NY 10029, USA.

\section{Authors' contributions}

SS and JO carried out all the experiments and data analyses. LG provided the lentiviral vectors and relevant protocols, in addition to supervising the lentivirus infection experiments. GM performed TGF $\beta$ assays with scleroderma auto-antibodies that were not included in the present manuscript. AG and FR designed the experiments and interpreted the data. SS and FR wrote the final manuscript. All authors have read and approved the final manuscript.

\section{Competing interests}

The authors declare that they have no competing interests.

Received: 9 September 2010 Accepted: 1 March 2011 Published: 1 March 2011

\section{References}

1. Hinz B, Phan SH, Thannickal VJ, Galli A, Bochaton-Piallat ML, Gabbiani G. The myofibroblast: one function, multiple origins. Am J Pathol 2007 170:1807-1816

2. Leask A, Abraham DJ: TGF $\beta$ signaling and the fibrotic response. FASEB J 2004, 18:816-827.
3. Ramirez F, Tanaka S, Bou-Gharios G: Transcriptional regulation of the human $\beta 2$ (I) collagen gene (COL1A2), an informative model system to study fibrotic diseases. Matrix Biol 2006, 25:365-372.

4. Shi Y, Massagué J: Mechanisms of TGF- $\beta$ signaling from cell membrane to the nucleus. Cell 2003, 63:515-524.

5. Moustakas A, Heldin CH: Non-Smad TGF- $\beta$ signals. J Cell Sci 2005 , 118:3573-3584

6. Geiser AG, Kim SJ, Roberts AB, Sporn MB: Characterization of the mouse transforming growth factor- $\beta 1$ promoter and activation by the Ha-ras oncogene. Mol Cell Biol 1991, 11:84-92.

7. Sheng H, Shao J, Dixon DA, Williams CS, Prescott SM, DuBois RN, Beauchamp RD: Transforming growth factor- $\beta 1$ enhances Ha-ras-induced expression of cyclooxygenase- 2 in intestinal epithelial cells via stabilization of mRNA. J Biol Chem 2000, 275:6628-6635.

8. Phanish MK, Wahab NA, Hendry BM, Dockrell ME: TGF- $\beta 1$-induced connective tissue growth factor (CCN2) expression in human renal proximal tubule epithelial cells requires Ras/MEK/ERK and Smad signaling. Nephron Exp Nephrol 2005, 100:e156-e165.

9. Stratton R, Rajkumar V, Ponticos M, Nichols B, Shiwen X, Black CM, Abraham DJ, Leask A: Prostacyclin derivatives prevent the fibrotic response to TGF- $\beta$ by inhibiting the Ras/MEK/ERK pathway. FASEB J 2002, 16:1949-1951.

10. Suzuki K, Wilkes MC, Garamszegi N, Edens M, Leof EB: Transforming growth factor $\beta$ signaling via Ras in mesenchymal cells requires p21-activated kinase 2 for extracellular signal-regulated kinasedependent transcriptional responses. Cancer Res 2007, 67:3673-3682

11. Thatcher JD: The Ras-MAPK signal transduction pathway. Sci Signal 2010, 3:trl1.

12. Ohtsu H, Suzuki H, Nakashima H, Dhobale S, Frank GD, Motley ED, Eguchi S: Angiotensin II signal transduction through small GTP-binding proteins: mechanism and significance in vascular smooth muscle cells. Hypertension 2006, 48:534-540.

13. Satoh T, Fantl WJ, Escobedo JA, Williams LT, Kaziro Y: Platelet-derived growth factor receptor mediates activation of ras through different signaling pathways in different cell types. Mol Cell Biol 1993, 13:3706-3713.

14. Lander HM, Hajijar DP, Hempstead BL, Mirza UA, Chait BT, Campbell S, Quilliam LA: A molecular redox switch on p21(ras). Structural basis for the nitric oxide-p21(ras) interaction. J Biol Chem 1997, 272:4323-4326.

15. Baroni SS, Santillo M, Bevilacqua F, Luchetti M, Spadoni T, Mancini M, Fraticelli P, Sambo P, Kazlauskas A, Avvedimento EV, Gabrielli A: Stimulatory autoantibodies to the PDGF receptor in systemic sclerosis. N Engl J Med 2006, 354:2667-2676.

16. Svegliati S, Cancello R, Sambo P, Luchetti M, Paroncini P, Orlandini G, Discepoli G, Paterno R, Santillo M, Cuozzo C, et al: Platelet-derived growth factor and reactive oxygen species (ROS) regulate Ras protein levels in primary human fibroblasts via ERK1/2. Amplification of ROS and Ras in systemic sclerosis fibroblasts. J Biol Chem 2005, 280:3674-36782.

17. Zhang W, Ou J, Inagaki Y, Greenwel P, Ramirez F: Synergistic cooperation between $\mathrm{Sp} 1$ and $\mathrm{Smad} 3 / \mathrm{Smad} 4$ mediates TGF $\beta 1$ stimulation of $\beta 2(\mathrm{I})$ collagen (COL1A2) transcription. J Biol Chem 2000, 275:39237-39245.

18. Fedorova E, Battini L, Prakash-Cheng A, Marras D, Gusella GL: Lentiviral gene delivery to CNS by spinal intrathecal administration to neonatal mice. J Gene Med 2006, 8:414-424.

19. Abe M, Harpel JG, Metz CN, Nunes I, Loskutoff DJ, Rifkin DB: An assay for transforming growth factor- $\beta$ using cells transfected with a plasminogen activator inhibitor-1 promoter-luciferase construct. Anal Biochem 1994, 216:276-284.

20. Fleming YM, Ferguson GJ, Spender LC, Larsson J, Karlsson S, Ozanne BW, Grosse R, Inman GJ: TGF $\beta$-mediated activation of RhoA signaling is required for efficient ${ }^{\mathrm{V} 12} \mathrm{HaRas}$ and ${ }^{\mathrm{V} 600 \mathrm{E}} \mathrm{BRAF}$ transformation. Oncogene 2009, 28:983-993.

21. Mori Y, Chen SJ, Varga J: Expression and regulation of intracellular SMAD signaling in scleroderma skin fibroblasts. Arthritis Rheum 2003, 48:1964-1978.

22. Guo X, Ramirez A, Waddell DS, Li Z, Liu X, Wang XF: Axin and GSK3- $\beta$ control Smad3 protein stability and modulate TGF- $\beta$ signaling. Genes Dev 2008, 22:106-120.

23. Massagué J: G1 cell-cycle control and cancer. Nature 2004, 432:298-306. 
24. Kapoor M, Liu S, Shi-wen X, Huh K, McCann M, Denton CP, Woodgett JR, Abraham DJ, Leask A: GSK-3 $\beta$ in mouse fibroblasts controls wound healing and fibrosis through an endothelin-1-dependent mechanism. $J$ Clin Invest 2008, 118:3279-3290

25. Daly AC, Vizan P, Hill CS: Smad3 protein levels are modulated by Ras activity and during the cell cycle to dictate transforming growth factor- $\beta$ responses. J Biol Chem 2010, 285:6489-6497.

26. Kretzschmar M, Doody J, Timokhina I, Massagué J: A mechanism of repression of TGF $\beta /$ Smad signaling by oncogenic Ras. Genes Dev 1999, 13:804-816.

27. Slack JL, Parker MI, Robinson VR, Bornstein P: Regulation of collagen I gene expression by ras. Mol Cell Biol 1992, 12:4714-4723.

doi:10.1186/1755-1536-4-8

Cite this article as: Smaldone et al:: Ha-Ras stabilization mediates pro-

fibrotic signals in dermal fibroblasts. Fibrogenesis \& Tissue Repair 2011 4:8.

\section{Submit your next manuscript to BioMed Central} and take full advantage of:

- Convenient online submission

- Thorough peer review

- No space constraints or color figure charges

- Immediate publication on acceptance

- Inclusion in PubMed, CAS, Scopus and Google Scholar

- Research which is freely available for redistribution

Submit your manuscript at www.biomedcentral.com/submit 